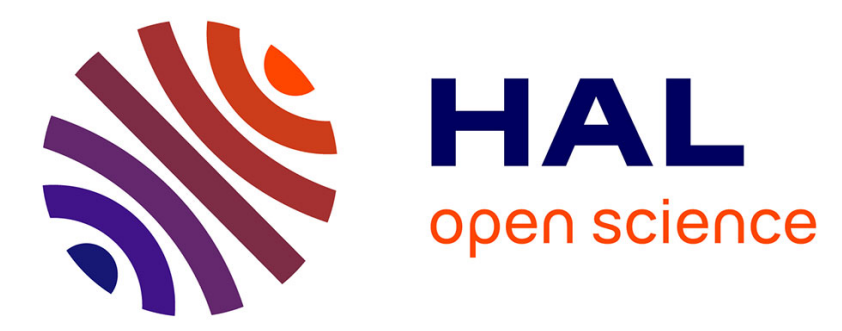

\title{
2. Morphology and dynamics of the Pinatubo aerosol layer in the northern hemisphere as detected from a ship-borne lidar
}

Bruno Nardi, Marie-Lise Chanin, Alain Hauchecorne, S. I. Avdyushin, G. F. Tulinov, M. S. Ivanov, B. N. Kuzmenko, I. R. Mezhuev

\section{To cite this version:}

Bruno Nardi, Marie-Lise Chanin, Alain Hauchecorne, S. I. Avdyushin, G. F. Tulinov, et al.. 2. Morphology and dynamics of the Pinatubo aerosol layer in the northern hemisphere as detected from a ship-borne lidar. Geophysical Research Letters, 1993, 20 (18), pp.1967-1970. 10.1029/93GL00486 . insu-03132029

\section{HAL Id: insu-03132029 \\ https://hal-insu.archives-ouvertes.fr/insu-03132029}

Submitted on 4 Feb 2021

HAL is a multi-disciplinary open access archive for the deposit and dissemination of scientific research documents, whether they are published or not. The documents may come from teaching and research institutions in France or abroad, or from public or private research centers.
L'archive ouverte pluridisciplinaire HAL, est destinée au dépôt et à la diffusion de documents scientifiques de niveau recherche, publiés ou non, émanant des établissements d'enseignement et de recherche français ou étrangers, des laboratoires publics ou privés. 


\title{
2. MORPHOLOGY AND DYNAMICS OF THE PINATUBO AEROSOL LAYER IN THE NORTHERN HEMISPHERE AS DETECTED FROM A SHIP-BORNE LIDAR
}

\author{
B. Nardi'1, M.-L. Chanin, A. Hauchecorne \\ Centre National de la Recherche Scientifique/Service D'Aeronomie, France
}

\begin{abstract}
S.I. Avdyushin, G.F. Tulinov, M.S. Ivanov, B.N. Kuzmenko, I.R. Mezhuev
Federov Institute of Applied Geophysics, Moscow, Russia
\end{abstract}

\begin{abstract}
Scattering ratios of the Pinatubo aerosol layer obtained by the ship-borne lidar of the Roscomhydromet of Russia on-board PROFESSOR ZUBOV are presented. During a campaign primarily in the low-latitude $\left(8^{\circ} \mathrm{N}-43^{\circ} \mathrm{N}\right)$ Atlantic Ocean, 48 days of data were obtained within the 73 day period spanning 11-July and 21-September of 1991 [Avdyushin et al., 1992]. These data show the aerosol cloud to be primarily in the 16-27 km altitude region, with a high degree of variability in the vertical structure and in the longitudinal structure, and to a lesser degree, in the latitudinal structure. Scattering ratios of up to 50 were recorded in the multi-layered structure which was often observed. These are the first lidar observations showing a high degree of zonal variability of the vertical structure of the aerosol layer. We show the latitudinal range of the Pinatubo aerosol cloud in the northern hemisphere over a 2 month period and estimate the latitudinal dispersion rate for the months of the measurements to be approximately $5^{\circ}$ latitude per month. A clear periodic variability was observed in the altitude structure during the entire data-set primarily within $8^{\circ} \mathrm{N}-22^{\circ} \mathrm{N}$ latitude and within the altitude region of the layer, from which a mean zonal wind profile was produced by a spectral analysis of the aerosol profiles.
\end{abstract}

\section{Introduction}

Intensive study of the Pinatubo aerosol layer is warranted not only by the unique opportunity to obtain a large quantity of information about the chemistry and dynamics in the stratosphere, but for more immediate concerns regarding problems produced by the high aerosol content to remote sensing observations as well. Preliminary studies of numerous observations of the Pinatubo aerosol layer have already been reported [GRL, January 1992, special issue]. The Sage II and NOAA/11 satellites have given exceptional pictures of the global extent of this aerosol cloud [McCormick and Veiga, 1992; Stowe et al., 1992], however the vertical penetration of these instruments is limited by the high optical depth of the aerosol layer. In addition, several sets of lidar observations were reported, including the airborne observations of Winker and Osborn [1992] and the ground based lidar observations of DeFoor et al. [1992] and Jäger [1992]. There also exists an extensive data-set obtained by the three Rayleigh lidar stations of CNRS [Avdyushin et al., this issue]. All these observations show clearly the multi-layered structure and variability of the aerosol cloud. However they have a limited geographic coverage. The ZUBOV lidar data presented here give a unique look at the vertical, geographical and temporal variability of the Pinatubo aerosol layer in the northern hemisphere.

\footnotetext{
${ }^{1}$ Visiting research fellow from The University of Michigan Space Physics Research Laboratory, Ann Arbor.

Copyright 1993 by the American Geophysical Union.

Paper number 93GL00486

0094-8534/93/93GL-00486\$03.00
}

\section{Aerosol Measurements}

The Rayleigh-Mie lidar on-board the ship PROFESSOR ZUBOV of the Roscomhydromet of Russia operates on the 539 $\mathrm{nm}$ wavelength, produced by a doubled yttrium-aluminum laser. The main characteristics of the lidar are given in Avdyushin et al. [1992, and this issue]. The statistical error of these relatively low-altitude measurements is negligible; the relatively high power of the laser, whose primary purpose is to take temperature measurements well into the mesosphere, results in an error of $<1 \%$ at $30 \mathrm{~km}$.

The aerosol profiles are given in terms of scattering ratio (SR), defined as:

$$
\operatorname{SR}(z)=\frac{\operatorname{Mie}(z)+\operatorname{Rayleigh}(z)}{\text { Rayleigh }(z)}
$$

where $\operatorname{Mie}(z)$ and Rayleigh(z) represent the components of the measured signal due to the Mie and Rayleigh backscattering, respectively. The lidar measured directly the quantity in the numerator. The denominator can be obtained in several ways, including experimentally, however we use the CIRA-86 model density to compute this term. This is possible since pure Rayleigh scattering is measured well above the level where aerosols are present (at $40 \mathrm{~km}$ and above) and the measured density can then be normalized with the model at these altitudes [Chanin and Hauchecorne, 1991]. The scattering ratio profiles were then extinction corrected.

The ship PROFESSOR ZUBOV traveled in the Atlantic Ocean for a period of 10 weeks during which these observations were made, tracing out a generally triangular pattern. The ship started taking measurements in the eastern Atlantic Ocean $\left(39^{\circ} \mathrm{N}, 28^{\circ} \mathrm{W}\right)$, after which it moved SW to the Cuba region, where it meandered slowly around, taking the greater part of the data-set. Subsequently, it traveled eastward between east Africa and Brazil $\left(8^{\circ} \mathrm{N}, 26^{\circ} \mathrm{W}\right)$, then northward near the west coast of Spain $\left(43^{\circ} \mathrm{N}, 10^{\circ} \mathrm{W}\right)$. Each night where measurements were possible, aerosol profiles were taken at a given location and for several periods during the night, lasting about 10 minutes each, every several hours in between routine Rayleigh temperature soundings. The data is presented here in the form of nightly averages. The maximum longitudinal displacement of the ship between two consecutive nights was approximately $6^{\circ}$, a relatively slow pace which justifies treating the ship as a quasi-stationary observation point.

It is advantageous to view the data-set initially in a three panel format. Figure 1 shows clearly the range of the measurements taken, as well as the primary physical characteristics inherent to the aerosol layer. The panels labeled [1] and [3] conveniently show the latitudinal structure of the aerosol cloud with a gap of approximately 2 months between the two 'pictures', while the panel labeled [2] shows a quasizonal cross section. During the time-span of these measurements, the layer seemed to be localized in the 16-27 $\mathrm{km}$ altitude region. There is a high degree of altitudinal structure in this region, which consists of multiple layers, which in turn are variable in magnitude and peak heights. The layers observed peaked predominantly near altitudes of $20 \mathrm{~km}$ and $24 \mathrm{~km}$. A high degree of zonal variability is evident in the 


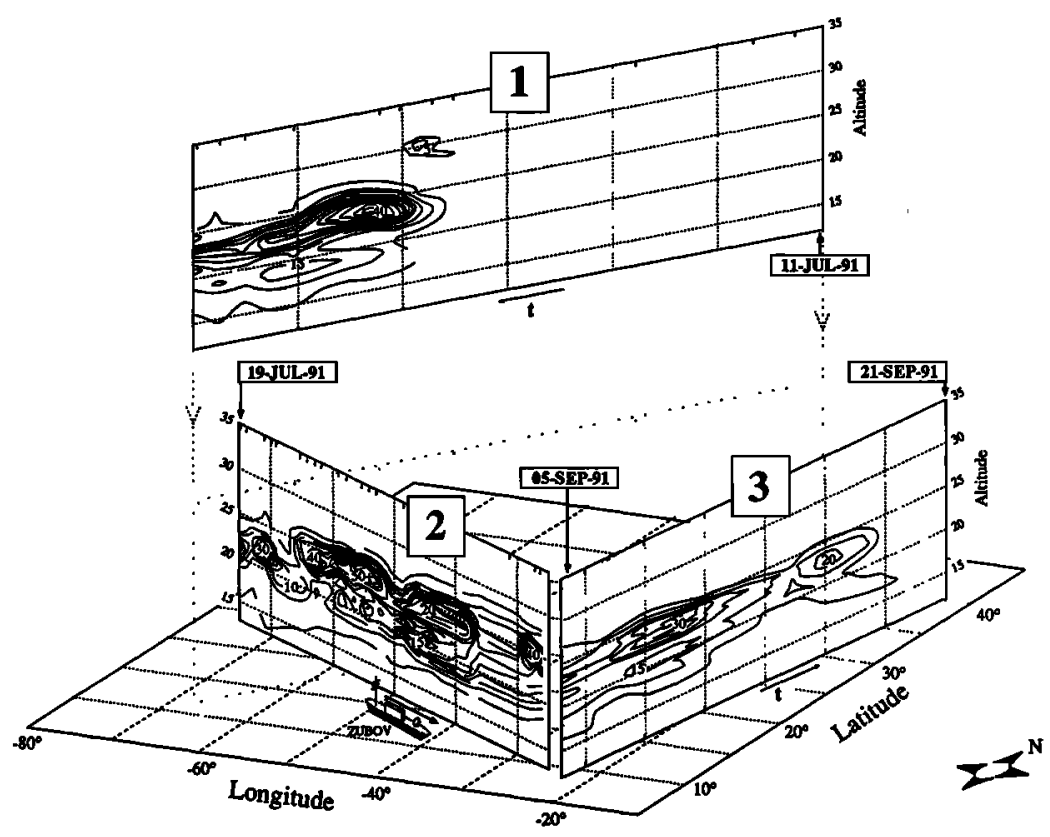

Fig. 1. The extinction corrected scattering ratio measurements from the ZUBOV-51 mission are shown in a 3-panel representation which roughly describes the path of the ship during acquisition of the data. Peak scattering ratios of 50 were observed at $24 \mathrm{~km}$ near $20^{\circ} \mathrm{N}$ latitude.

aerosol cloud and to a lesser extent there is also latitudinal structure. It should be stressed that zonal variability of the Pinatubo cloud shown in panel [2] does not actually describe the true longitudinal morphology. Since these measurements are made over a relatively long time period, they have temporal effects mixed into them (i.e., those produced by the zonal advection of aerosol clouds overhead). As the ship travels toward the East, morphological features are continuously being carried overhead toward the west, thereby making the longitudinal variability seem much more sharp.

$\AA$ more quantitative description of the relative magnitudes and vertical and temporal variability of the scattering ratio is shown in the multiple profile plot (Figure 2). Scattering ratio profiles are shown for 6 days within a span of 8 days at a nearly fixed latitude and within a $5^{\circ}$ longitude region. The clearly predominant layers observed are confirmed to be centered at $20 \mathrm{~km}$ and $24 \mathrm{~km}$, their peak scattering ratios being approximately 10 and 40 , respectively. Marked temporal variability in the scattering ratio magnitude occurred in the upper layer, which shows more than one order of magnitude increase, from $\sim 3$ to $\sim 50$, between 18-19 August 1991 .

The two latitude cross-sections are compared in greater detail in the color contours of Figure 3. It appears that the bulk of the aerosol cloud does not increase in altitude and does not change in latitude during the 2 months, however it does expand, indicating diffusion. In addition, the northern edge of the aerosol layer can be seen to extend poleward by approximately $10^{\circ}$ over the two month period, especially just above the tropopause, and to attenuate in magnitude to some extent. These observations confirm the recent result of the study by Trepte and Hitchman [1992], based on satellite observations of aerosol layers since 1979 , indicating that most of the poleward transport occurs at low altitudes whereas the bulk of the aerosols above $20 \mathrm{~km}$ remain within $20^{\circ}$ of the equator. One may object that the observed variability may be produced if the latitude cross-sections do not represent the same meridional plane of the cloud. However, from the relative observed magnitudes of the maxima of the peaks and

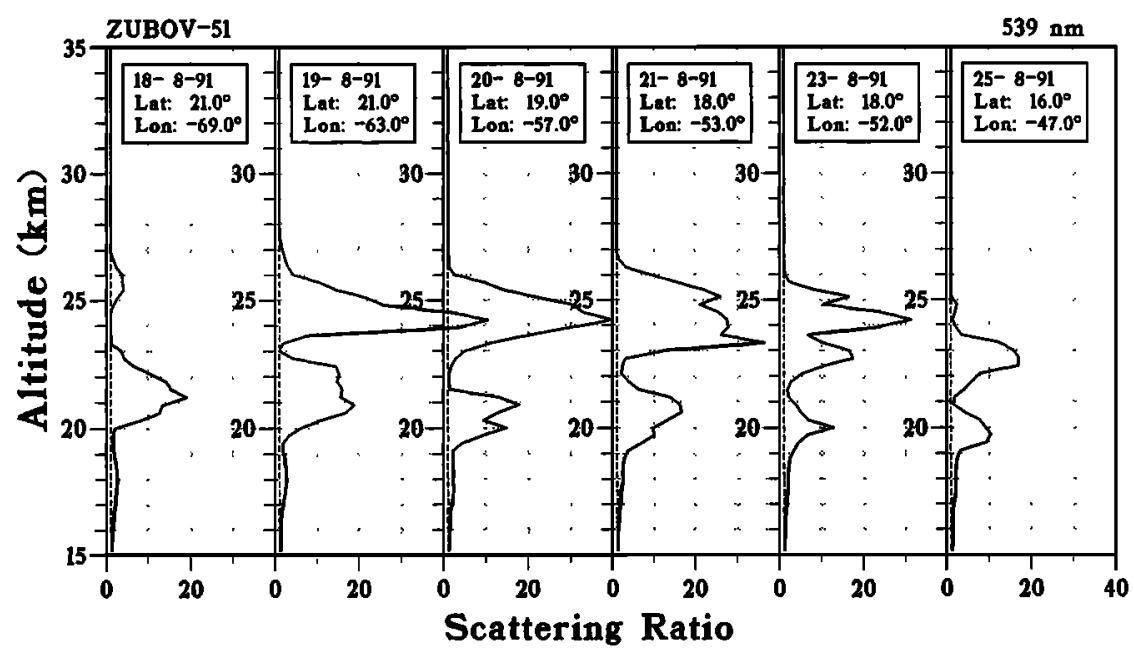

Fig. 2. Several nearly-consecutive nightly mean scattering ratio profiles show a predominant double layer structure as well as a very high degree of variability in the observed magnitudes. 


\section{Scattering Ratio at $539 \mathrm{~nm}$}
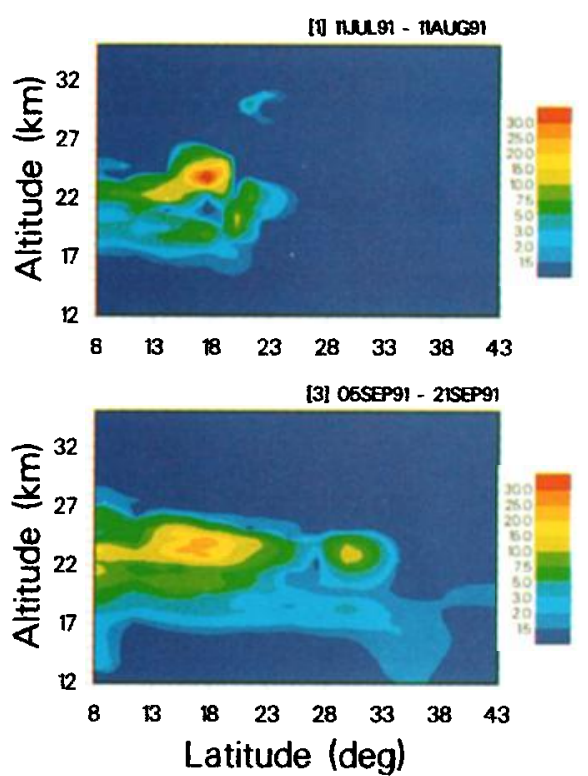

Fig. 3. Two scattering ratio plots corresponding to mean dates (a) mid-July and (b) mid-September show the change in the latitudinal structure of the aerosol layer over a period of approximately two months.

considering the relatively slow motion of the ship and the nature of the zonal variation, it seems that this is not the case.

Diffusion coefficients can be calculated for the region of the strong aerosol feature shown in Figure 3 , roughly at $24 \pm 2 \mathrm{~km}$ altitude and $18^{\circ} \pm 3^{\circ} \mathrm{N}$ latitude, assuming the relationship $D=\Delta\left(\phi^{2}\right) / \Delta$ t. The results are: $D_{\text {horiz }} \approx 1.0 \times 10^{5} \mathrm{~m}^{2} / \mathrm{s}, D_{\text {vert }} \approx$ $2.9 \times 10^{-3} \mathrm{~m}^{2} / \mathrm{s}$, where approximate values for $\phi$ are obtained from the FWHM (full width at half maximum) of the strong aerosol features (where $S R=20$ ) and $\Delta t$ is the time difference between the average date of each plot, 49 days.

The clear zonal variability observed suggests that it would be interesting to view the entire data-set as a function of time (Figure 4), assuming the ship to be a quasi-stationary point. This assumption is justified by the relatively slow speed of the ship (maximum: $\sim 600 \mathrm{~km} /$ day or $7.5 \mathrm{~m} / \mathrm{s}$ ) as well as the relatively localized geographic region in which it operated. Figure 4 shows a clear periodically occurring pattern in the aerosol structure. It appears that a plume-like structure is

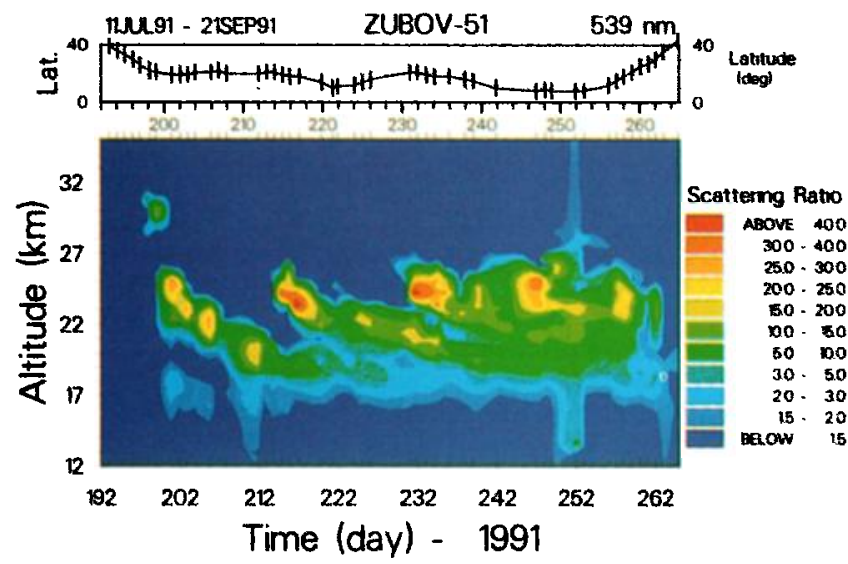

Fig. 4. The entire data-set of vertical scattering ratio profiles is shown as a function of time, revealing a nearly cyclic pattern in the vertical structure of the aerosol layer with a period of approximately $16+$ days. (The overlaying line plot above indicates the position of the ship in terms of latitude.)

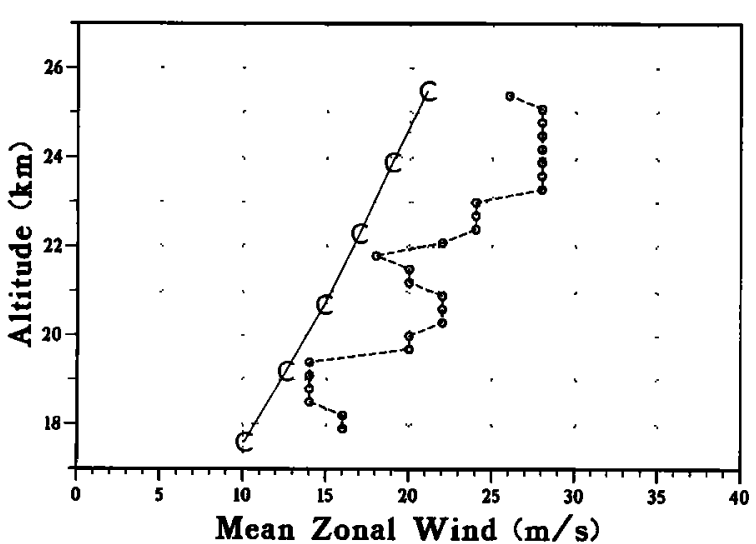

Fig. 5. The vertical profile of the mean zonal wind as obtained from the harmonic term at each altitude with the maximum power $(-)$ and compared with the CIRA-86 model $(-G)$. Positive wind indicates a wind from east to west. The data correspond to a latitude strip, $8^{\circ}-22^{\circ} \mathrm{N}$ and a 73 day period centered at 18-August; the CIRA-86 model values correspond to August, $15^{\circ} \mathrm{N}$ latitude.

passing overhead, the densest, highest portion first, followed by the progressively lower and less dense tail. The periodic pattern observed became increasingly smeared as time progressed which reinforces the assumption that diffusion is spreading the aerosols. This temporal picture suggests that the highly layered structure is produced by a positive gradient in the magnitude of the mean zonal wind, which causes the top end of the volcanic plume to travel around the world at a faster rate than the lower part, stretching it as it is carried zonally and causing it to spiral around itself on the global scale, so that for any given measurement we are seeing a cross-section of several of the coils, each of which appears as a layer.

At first glance, the periodicity is on the order of 18 days, which is what would be expected for a cloud feature that was being transported zonally at the rate of $20^{\circ}$ per day $(25 \mathrm{~m} / \mathrm{s})$, the approximate stratospheric mean zonal transport rate expected for this latitude and season [CIRA-86]. This implies that over the 70 day observation period, we are in fact seeing the same morphological features passing repeatedly overhead and confirms the a priori assumption that the ship was a quasistationary observation point. A spectral analysis of these data on a per-altitude basis yields a vertical profile of the mean zonal wind.

\section{Spectral Analysis}

The vertical scattering ratio profiles in the latitude region, $8^{\circ} \mathrm{N}-22^{\circ} \mathrm{N}$, were first binned in altitude and time as shown in Figure 4. The data is then treated as a vertically stacked series of horizontal strips, each of which is subjected to a spectral analysis. The clearly dominant term at each altitude, if one exists, is a direct indication of the mean zonal wind speed at that altitude.

A discrete fast-Fourier-transform was used to obtain the power distribution for the frequency terms. In order to improve the frequency resolution, we used an over-sampling interval of 224 days. This interval was chosen to produce a frequency resolution (lowest harmonic term) equivalent to a zonal wind speed of $2 \mathrm{~m} / \mathrm{s}$ at $15^{\circ}$ latitude. The mean vertical profile was used to extend the range of the data-set beyond the 72 day period for which data actually existed. The harmonic with the maximum power at each altitude is then plotted and gives directly the vertical profile of the mean zonal wind (Figure 5). The harmonic terms at the extreme ends of the spectrum are omitted since large values may be produced by the gradients which necessarily exist at the boundaries between the real data and the averaged profiles in the over-sampling domain. The small scale vertical structure of the resulting 
zonal wind profile is also an artifact of the spectral analysis and should not be believed, since the profile is highly averaged due to the nature of the analysis of the data-set. Comparison with the CIRA-86 model shows relatively good agreement, though slightly higher values than the CIRA-86 model are observed. This can be explained in part by the quasi-biennial oscillation (QBO) at these low latitudes. The QBO is expected to be westward during the months of the ZUBOV measurements and could have enhanced the actual westward wind above the CIRA-6 predicted average.

A systematic error, analogous to a Doppler shift, is introduced into the wind profile because the ship is not actually stationary. For example, as the ship moves toward the east, it observes westward moving cloud features to be moving faster because it detects them sooner. If the ship was moving at full speed westward (6\% day here) it would introduce a maximum error of $7.5 \mathrm{~m} / \mathrm{s}$. In fact the ship was not always moving at full speed and was often moving in the reverse direction thus producing a zonal smearing effect which would tend to mask the periodicity rather than to introduce a net shift. However, this systematic error was compensated for by introducing a time correction to the dates of the measured profiles, obtained from the rate of longitudinal displacement of the ship between consecutive nights of measurements. The time-shift correction is dependant on the zonal wind and therefore on altitude as well. The corrected time that compensates for the ship's zonal motion at each altitude, $t_{i}^{\prime}\left(z_{j}\right)$, is:

$$
t_{i}^{\prime}\left(z_{j}\right)=t_{i}+\frac{\Delta s_{i}}{u\left(z_{j}\right)}
$$

where,

$$
\Delta s_{i}=\left(\lambda_{j}-\lambda_{\text {ref }}\right) \cos \bar{\phi}
$$

where $z_{j}$ is altitude of layer $j, u\left(z_{j}\right)$ is the estimated mean zonal wind, $t_{i}$ is the time corresponding to profile $i, \Delta s_{i}$ is the zonal distance of the ship from an arbitrary reference spot. $\lambda_{i}$ and $\lambda_{\text {ref }}$ are the longitudes at profile $i$ and at the reference position, respectively and $\phi$ is the mean latitude of the profiles, $15^{\circ}$. Since the individual shifts for most nights are significantly smaller than the calculated maximum, and are since they occur in both directions, the resulting correction on the wind profile is very small, at less than $5 \%$.

\section{Conclusions}

The zUBOV data-set offered a unique perspective of the vertical, horizontal and temporal behavior of the Pinatubo aerosol cloud in the northern hemisphere. A high degree of vertical structure was observed, with scattering ratios (at 539 $\mathrm{nm}$ ) reaching values of 50 . However, there was a predominance of two aerosol layers at approximately $20 \mathrm{~km}$ and $24 \mathrm{~km}$, with maximum observed scattering ratios of 19.5 and 51, respectively. The altitudes of these aerosol peaks did not appear to rise appreciably in altitude over the duration of these measurements. However vertical variation does exist to a large degree and can be attributed to the advection of zonal structure over a local observation point. The latitudinal dispersion rate for these months is estimated at $\sim 5^{\circ}$ per month. In addition, a horizontal and vertical smearing effect was observed in the aerosol cloud structure, apparently due to (turbulent) diffusion. Horizontal and vertical diffusion coefficients: $D_{\text {horiz }} \approx 1.0 \times 10^{5} \mathrm{~m}^{2} / \mathrm{s} ; D_{\text {vert }} \approx 2.9 \times 10^{-3} \mathrm{~m}^{2} / \mathrm{s}$, were obtained from rough calculations based on this observed smearing. A clearly periodic variability in the observed vertical structure indicates that large scale aerosol features were repeatedly passing overhead. Spectral analysis yields a mean zonal wind profile in the altitude region $17-26 \mathrm{~km}$ of $12-29$ $\mathrm{m} / \mathrm{s}$ toward the west, slightly higher than the values predicted by the CIRA-86 model for August, $15^{\circ} \mathrm{N}$.

Acknowledgements. The contribution to this work by B. Nardi was supported by the NSF Program for Long and Medium Term Research at Foreign Centers of Excellence; grant number INT/9101978 to the University of Michigan.

\section{References}

Avdyushin, S.I., G.F. Tulinov, M.S. Ivanov, B.N. Kuzmenko, I.R. Mezhuev, Y.P. Dudoladov, Lidar observations of Pinatubo eruption products in the Atlantic stratosphere from PROFESSOR ZUBOV and PROFESSOR VIZE research ships. Report of the Academy of Science of Russia [in press, 1992].

Avdyushin, S.I., G.F. Tulinov, M.S. Ivanov, B.N. Kuzmenko, I.R. Mezhuev, B. Nardi, M.-L. Chanin, A. Hauchecorne, 1. Spatial and temporal evolution of the optical thickness of the Pinatubo aerosol cloud in the northern hemisphere from a network of ship-borne and stationary lidars, Geophys. Res. Lett., [this issue].

Chanin, M.-L., A. Hauchecome, Lidar study of the structure and dynamics of the middle atmosphere, Indian J. Radio Sp. Sci., 20, 1-11, 1991.

DeFoor, T.E., E. Robinson, S. Ryan, Early lidar observations of the June 1991 Pinatubo eruption plume at Mauna Loa Observatory, Hawaii, Geophys. Res. Lett. 19, 187-190, 1992.

Hauchecorne, A, M.-L. Chanin, P. Keckhut, Climatology and trends of the middle atmospheric temperature (33-87 $\mathrm{km}$ ) as seen by Rayleigh lidar over the south of France, $\underline{\mathrm{J}}$. Geophys Res., 96, 15297-15309, 1991.

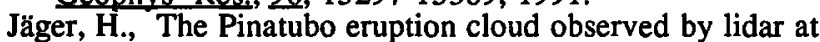
Garmisch-Partenkirchen, Geophys. Res. Lett., 19, 191$194,1992$.

McCormick, M.P., R.E. Veiga, SAGE II measurements of early Pinatubo aerosols, Geophys. Res. Lett., 19, 155 158, 1992.

Plumb, R.A., J.D. Mahlman, The zonally averaged transport characteristics of the GFDL General Circulation / Transport Model, J. Atmos. Sci., 44, 298-327, 1987.

Rees, D., J.J. Barnett, K. Labitzke (Eds.), COSPAR International Reference Atmosphere: 1986, Part II: Middle Atmosphere Models, Advances in Space Research, 519 pp., Vol. 10, No. 12, Pergamon Press, Oxford, 1990.'

Stowe, L.L., R.M. Carey, P.P. Pellegrino, Monitoring the Mt. Pinatubo aerosol layer with NOAA/11 AVHRR data, Geophys. Res. Lett., 19, 159-162, 1992.

Trepte, C.R., M.H. Hitchman, Tropical stratospheric circulation deduced from satellite aerosol; data, Nature, 355, 626-628, 1992.

Winker, D.M., M.T. Osborn, Airborne lidar observations of the Pinatubo volcanic plume, Geophys. Res. Lett., 19. 167-170, 1992.

S. I. Avdyushin, M. S. Ivanov, B. N. Kuzmenko, I. R. Mezhuev, G. F. Tulinov, Federov Institute of Applied Geophysics, Rostokinskaya st. 9, 129226 Moscow, Russia. M.-L. Chanin, A. Hauchecorne, B. Nardi, Service D'Aéronomie, Centre National de la Recherche Scientifique, B.P. №. 3, 91371 Verrières le Buisson CEDEX, France.

(Received: 24 August 1992; revised: 16 December 1992; accepted: 20 January 1993 ) 